\title{
Applying Complex Adaptive Systems Theory to Understand Distributed Participatory Design in Contemporary, Crowdsourced Information Systems Development
}

\author{
Karlheinz Kautz \\ School of Business IT and Logistics, \\ RMIT University, Melbourne, Australia \\ karlheinz.kautz@rmit.edu.au \\ Gro Bjerknes \\ Faculty of IT, \\ Monash University, Melbourne, Australia \\ Julie Fisher \\ School of Business IT and Logistics, \\ RMIT University, Melbourne, Australia \\ Tomas Jensen \\ Communication, Knowledge \& Change \\ (Formerly United Nations Children's Fund), \\ Cairns, Australia
}

\begin{abstract}
Contemporary information systems development (ISD) takes place in a dynamic environment; it is generally acknowledged as a complex activity. It has been proposed that ISD projects should be viewed as a complex adaptive system (CAS) and that these projects are better understood through the application of CAS. Distributed participatory design (DPD) is an approach to contemporary ISD where different, geographically dispersed stakeholders, often called the crowd, participate voluntarily and typically unaffiliated with the development organisation in the development and design of information systems in distributed design teams which are mostly online on Internet, web-based, and social media platforms. Going beyond individual methods, techniques, and practices, the objective of this research is twofold as we answer the two research questions: how are DPD projects in crowdsourced ISD managed and performed in their entirety and how does CAS theory provide plausible explanations and contribute to an understanding of contemporary ISD? For this purpose, we present a case of DPD in crowdsourced ISD in an intergovernmental, not-for-profit environment in the context of a DPD project which engaged Pacific Youth in the development of a digital game where we applied CAS theory to better understand and gain insights for ISD theory and practice.
\end{abstract}

Keywords: Contemporary Information Systems Development, Distributed Participatory Design, Complex Adaptive Systems Theory.

\section{Introduction}

Contemporary information systems development (ISD) takes place in a dynamic environment; it is generally acknowledged as a complex activity (Truex et al., 1999; Highsmith 2000; Meso and Jain 2006, Kautz 2012). Benbya and McKelvey (2006) present an analysis of sources of 
complexity in contemporary ISD, and recognise as such: changing user requirements, organizational needs, and external competitive conditions; increased interdependencies among the involved individuals, organizations and technologies; and the rapid evolution of IS and IT. They purport that ISD is often viewed as a complex top-down process and lament the fact that such a perspective falls short in dealing with the often unexpected contingencies of the ISD process.

As an alternative, they put forward a conception of ISD based on complexity theory (Kauffman 1993; Holland 1995; Holland 1998) and propose that ISD projects should be viewed as a complex adaptive system (CAS) and that these projects are better understood through the application of CAS where complexity generally refers to an emergent property of systems that are made of large numbers of self-organising agents that interact in a dynamic and non-linear fashion. CAS theory studies how a complex system can adapt to its environment and how innovative properties of a system emerge from the interactions of its components (Vidgen and Wang 2009).

CAS theory has been extensively applied in management studies, with Benbya and McKelvey (2006) and Vidgen and Wang (2009) providing two comprehensive summaries of this literature. There are also writings on the topic in the IS domain (Jacucci et al. 2006; Merali and McKelvey 2006), as well as specific research on CAS and ISD (Highsmith 2000; Jain and Meso 2004; Benbya and McKelvey 2006; Meso and Jain 2006; Vidgen and Wang 2006; Vidgen and Wang 2009; Kautz and Madsen 2010; Kautz 2012). In ISD, the work has mostly been either conceptual or in the area of agile software development. Vidgen and Wang (2009) lament a scarcity of empirical research on CAS in the IS field which they relate to the difficulty of turning the quite abstract concepts of CAS theory into sufficiently concrete case study research and thus call for more research that on a CAS theory background examines closely how development practices are actually implemented and performed. With the work presented here we provide such an empirical case study of an ISD project.

Distributed participatory design (DPD) is one form of contemporary ISD. It has its roots in participatory design (PD) which is an ISD and design approach whose central tenet is the participation of people, users as equal design partners in the co-design of the information systems and technologies (IS/IT) that they are supposed to use themselves (Kensing and Blomberg 1998; Lukyanenko et al. 2016). It originally developed in the 1970s in Scandinavia and focused on user participation in internal organisational settings in the development of dedicated, tailor-made IS/IT which were to be used in the workplace. Thus, most studies of PD examine the development of a single, customised information system that typically supports workflows within a single client organisation (Obendorf et al. 2009).

Since its beginnings PD has progressed to also consider non-organisational as well as community-driven contexts (Lukyanenko et al. 2016). Participation by less formally organised communities and the crowd in the development of content producing community-based service systems has challenged existing ISD and PD approaches (Öberg et al. 2009; Kazman and Chen 2009; DiSalvo et al. 2013; Lukyanenko et al. 2016). The nature of participation in such design and development processes is emergent and cannot be fully controlled (Markus and Mao 2004). To cope with these new contexts and forms of work and participation - such as communities and virtual networks - traditional PD expanded to deal with the diversification of stakeholders and with settings where stakeholders are distributed across various dimensions of time, space and organisational structures (Obendorf et al. 2009). The concept of 
distributed participatory design (DPD) refers to the participation of different stakeholders in distributed design teams, mostly online, through Internet, web-based, and social media platforms where user participation in online projects is primarily voluntary and the participants are typically unaffiliated with the development organisation ${ }^{1}$ (Lukyanenko et al. 2016). Declaring a dearth of research Clement et al. (2008) as well as DiSalvo and DiSalvo (2014) request more studies on how to conduct PD in new environments. Much of the existing research on DPD focusses on individual methods, techniques, and practices such as mediated feedback, commented case studies, and surveys (Gumm et al. 2006) as well as probe blogs, idea, concept, and feature postings, commenting, voting and online testing (Näkki and Koskela-Huotari 2012). To go beyond these individual methods, techniques, and practices Markus and Mao (2004) ask to extend research on participatory approaches to ISD transcending conventional settings, roles and types of participants and contributors.

Following these calls for more investigations into CAS and DPD the objective of our research presented here is therefore twofold and we pose the following questions: how are DPD projects in crowdsourced ISD managed and performed in their entirety and how does CAS theory provide plausible explanations and contribute to an understanding of contemporary ISD? To pursue our research objectives and to answer the research questions, we studied a case of DPD in crowdsourced ISD in an unconventional setting in an intergovernmental, notfor-profit environment in the context of an UNICEF (Pacific) ${ }^{2}$ initiated DPD project which engaged Pacific Youth in the development of a Facebook based digital game which had the objective to raise awareness about climate change challenges in that region (Fisher 2012). Thus, we validate and confirm existing theory in a new setting and provide practical advice for performing contemporary ISD.

The remainder of the article is structured as follows: The next section introduces our theoretical background and analytical framework in more detail. Our research approach is explained in section 3 and a case narrative is provided in section 4 . Section 5 includes the analysis of the DPD and ISD process in the case setting; it also discusses our findings and their implications for research and practice. We finish with our conclusions and a summary of our contributions in Section 6.

\section{Theoretical Background: CAS Theory}

As stated above CAS theory has been recognized as a valuable approach to understanding contemporary ISD. As one of the first authors Highsmith $(2000,2002)$ reflecting on his extensive experience as ISD consultant and practitioner put forward that agile development approaches as an instance of ISD draw on CAS theory as their foundation. Subsequently several research teams have applied the theory and provided organising principles and suggestions for best practice for the ISD process which we in the following briefly review here.

\footnotetext{
${ }^{1}$ In this context, it has been argued that the free/libre/open source software development (FLOSS) approach represents a specific form of DPD (Titlestad et al. 2009); however, with its focus on technical development of source code by mostly highly tech-savvy software developers and programmers we will here not consider this otherwise very interesting strand of work further.

2 The United Nations Children's Fund (UNICEF) is a United Nations (UN) non-government, non-forprofit organisation and program that provides humanitarian and development assistance to children and mothers in developing countries. For the remainder of this article, we will refer to UNICEF (Pacific Islands Countries) as UNICEF (P).
} 
Benbya and McKelvey (2006) present some conceptual work, focusing on the co-evolutionary aspect of CAS, and put forward seven rather abstract principles of adaptive success, and discuss their bearings on ISD problems. Their advice is quite abstract and, in parts, not easy to implement.

Meso and Jain (2006) identify seven principles of CAS which, to some extent, overlap with those described by Benbya and McKelvey (2006), but whose meanings are more intuitive and easier to grasp. They are the principles of open systems, interactions and relationships, transformative feedback loops, emergent behaviour, distributed control, shallow structure, and growth and evolution. The authors provide a conceptual argument that they support with various examples from the literature. They map the principles to agile development practices, and from this mapping derive more concrete, yet generic recommendations for best practices for ISD.

Vidgen and Wang (2009) with a focus on co-evolution and agile development develop a framework and summarise the key concepts of CAS in three guiding principles for the organization of agile software development as matching co-evolutionary change rate, optimizing self-organisation, and synchronising concurrent exploitation and exploration. Based on an empirical case, they identify six capabilities as enablers of agility in agile teams grounded in CAS, namely, co-evolution of IT team and customer to create business value; sustainable working with rhythm; collective mindfulness; sharing and team learning; process adaptation and improvement; product innovation. Kautz and Madsen (2010) provide similar findings, also basing their research on the objective of understanding agile software development.

Extending this work Kautz (2012) shows how CAS and CAS principles are advantageous for comprehending and organising ISD in general, beyond any particular development approach chosen for the execution of a project such as agile development. In an empirical account of contemporary ISD he identifies a number of practices and provides practical advice to cope with complexity in ISD in an adaptive manner. The practices are similar to those depicted by Meso and Jain (2006) and Vidgen and Wang (2009), but he argues that rather than being enablers for agility, these practices are properties of complex adaptive systems.

There is however no single and fully shared definition of CAS and no unifying CAS theory, therefore our theoretical background is based on Vidgen and Wang's (2009) literature review which takes both the original CAS literature and its applications in managerial, organisational and IS studies into account.

A complex adaptive system consists of a large number of loosely interconnected and interacting autonomous parts or agents, each of which behaves according to some set of, sometimes rather simple, rules. These rules require agents to adjust their behaviour to that of other agents with whom they interact. The resulting system behaviour can be very complex (Vidgen and Wang 2009). Interaction is a significant concept in this context, as "the behaviour of the system is determined by the nature of these interactions, not by what is contained within the components. Since the interactions are rich, dynamic, nonlinear, and are fed back, the behaviour of the system as a whole cannot be predicted from the inspection of its components. The notion of "emergence" is used to delineate this aspect" (Jain and Meso 2004 citing Cilliers 2000). CAS theory rests on the idea that order emerges through the interaction of the agents (Benbya and McKelvey 2006). Emergence is the property of CAS which creates some greater property of the whole, the system behaviour results from the interaction of the parts and the 
agent behaviours; however, the emergent system behaviour cannot be predicted or fully explained from the measured behaviours of the agents (Highsmith 2000). Interaction and emergence are closely related, and link together other generally acknowledged properties of CAS. Beyond the interconnected autonomous agents, a number of concepts are frequently used when discussing CAS. These concepts which we briefly introduce below are selforganisation, co-evolution, the poise at the edge of chaos, time pacing, and the poise at the edge of time. We have described and applied these concepts earlier in a detailed analysis of an ISD project which used agile systems development and project management practices (Kautz 2012).

Interconnected autonomous agents, human or non-human, have the ability to independently intervene and determine what action to take, given their perception of their environment. Yet, they are interconnected and interact in such a way that they collectively or individually are responsive to change around them, but not overwhelmed by the information flowing to them by this connectivity (Mitleton-Kelly 2003).

Self-organisation is the capacity of interconnected autonomous agents to evolve into an optimal organised form without external force. It results from the agents' interaction in a disciplined manner within locally defined and followed rules and, as such, requires a departure from command and control management (Volberda and Levin 2003; Vidgen and Wang 2009).

Co-evolution relates to the fact that a CAS and/or its parts alter their structures and behaviours at a sustainable change rate in response to the interactions of its parts and to the interaction with other CAS that co-exist in an ecosystem where adaptation by one system affects the other systems. This leads to further adaptations and reciprocal change where the systems do not evolve individually, but concertedly (Kauffman 1993; Vidgen and Wang 2009).

Poise at the edge of chaos describes the ability of a CAS to be at the same time stable and unstable, to never quite lock into place, yet never quite fall apart. The edge is the place that provides not only the stimulation and freedom to experiment and adapt as well as for novelty to appear, but it also allows for the sufficient frameworks and structures to avoid disorderly disintegration. This gives a competitive advantage: CAS that are driven to the edge of chaos out-compete those that are not (Brown and Eisenhardt 1998; Anderson 1999; Stacey 2003; McMillian 2004; Vidgen and Wang 2009).

Time pacing in this context indicates that a CAS creates an internal rhythm that drives the momentum of change. Change in a CAS is triggered by the passage of time rather than the occurrence of events; this stops them from changing too often or too quickly (Brown and Eisenhardt 1998; Vidgen and Wang 2009).

Poise at the edge of time conceptualizes a CAS's attribute of simultaneously being rooted in the present, yet being aware of the future and its balance as well as synchronization between engaging enough exploitation of existing resources and capabilities to ensure current viability with engagement of enough exploration of new opportunities to ensure future viability (Brown and Eisenhardt 1998; Volberda and Levin 2003; Vidgen and Wang 2009).

All these core concepts are heavily intertwined and mutually reinforcing (Vidgen and Wang 2006). Thus, CAS can be characterized through the emergence of co-evolutionary, selforganised behaviour, structure and order through the interaction of interconnected autonomous agents in a time-paced rhythm balanced at the edge of time. At the heart of CAS 
theory's relevance for ISD is the concept of emergence which appears in relation to all key concepts (Highsmith 2000; Kautz 2012):

(1) as emergent order resulting from self-organising agent interactions (Kauffman 1993; Holland 1995),

(2) as the emergence of team learning as a result of the interaction and capabilities of interconnected autonomous agents (Mitleton-Kelly 2003),

(3) as truly emergent self-organisation in contrast to a premeditated or deliberately implemented one by management (Stacey 2003),

(4) as co-evolutionary emergent behaviour and structure (Benbya and McKelvey 2006) or even emergent co-evolution (Kelly 1994),

(5) as the region of emergent complexity, the edge of chaos (Benbya and McKelvey 2006),

(6) as rhythm considered an emergent state of working in the context of time pacing (Vidgen and Wang 2009), and

(7) as emergent balance between exploitation and exploration at the edge of time (Bocanet and Ponsiglione 2012).

\section{Research Approach and Method}

Our research follows the interpretive paradigm and as such takes a hermeneutic stance; accordingly we perform and secure the validity of our work through the application of an established set of principles for conducting and evaluating interpretive studies in information systems that suggests that all human understanding is achieved by iterating between considering the interdependent meaning of the parts and the whole that they form (Klein and Myers 1999). These principles are the fundamental principle of the hermeneutic circle, the principle of contextualisation, the principle of interaction between the researchers and the subjects, the principle of abstraction and generalisation, the principle of dialogical reasoning, the principle of multiple interpretations, the principle of suspicion. This approach covers and extends other measures as for example put forward by Venkatesh et al. (2013) to obtain design as well as analytical and inferential validity of qualitative research in general. In the following will we describe how we have applied the listed principles in this research.

In line with our hermeneutical perspective, we also applied a hermeneutic approach for conducting literature reviews that recognises a literature review as an iterative process of developing understanding that is emergent, unpredictable and creative, rather than straightforward, orderly and strictly prescribed (Boell and Cecez-Kecmanovic 2014). It has, as Baiyere (2017) has put it "the advantage of a terse and pithy presentation of prior research and gives room for more conceptual reasoning over the tendency to re-list articles." This fits well with the overarching aim of our research that is to challenge the widely accepted knowledge about ISD to advance theory in that area. Alvesson and Sandberg $(2011,2013)$ have described this approach to research as assumption-challenging rather than 'gap-spotting' and have labelled it as generating research questions through problematisation (Alvesson and Sandberg 2011).

Given the limited literature concerning DPD in crowdsourced ISD and how it unfolds, our investigation is based on an exploratory, qualitative case study (Creswell 2003) of an ISD 
project. The project utilised a social media platform and involved a number of different organisational units and stakeholder groups including numerous youths as participants. While it is often stated that it is not possible to theorise and to generalise from a single case study, Walsham (1995) suggests that it is possible to generalise case study findings among others in the form of a contribution of rich insight. In contrast to a representative case selection we selected a revelatory case which has not been described in the IS literature before; such cases are considered to be prototypical of the phenomenon of interest (Gerring 2007) and by studying such a case we were able to illuminate key aspects of the phenomenon under investigation. On this background we used the key concepts of CAS theory in a new setting for our data analysis and followed the principle of abstraction and generalisation. As such, our findings exhibit an instance of theorising through idealisation (Ghazawneh and Henfridsson 2013) which needs to be further validated.

The roles and length of stay in the field varied for the four authors of this paper. The fourth author has been involved in the project as a reflective practitioner (Schön 1983) throughout the whole period. As the UNICEF (P) communications specialist and project sponsor, he was involved as the overall project co-coordinator at all stages of the project. He shared correspondence and provided reflections on the process. As an employee and insider, he enhanced the depth and breadth of understanding the case setting that may not be accessible to a non-native researcher (Kanuha 2000). The third author also participated during the whole project, as an involved, accompanying researcher (Walsham 1995) and academic consultant. Initially involved in the establishment of the technical development team and its coordination and communication protocol, and although later only occasionally providing advice to the project team and otherwise observing the development process she had an impact on the design and development of the game.

Given the background of these authors the purpose of the research presented here was to investigate in a less unbiased manner how DPD takes place in practice. Thus, the first and the second author acted as outside observers (Walsham 1995) and were included in the reflective process. They conducted interviews with the involved researcher and academic consultant and independently analysed all available empirical material and as such took the principle of interaction between the researchers and the subjects into account. During the analysis the two first authors regularly discussed their emerging results with the two others and incorporated their feedback. Through this process our study followed the principles of multiple interpretations, dialogical reasoning, and suspicion. The combination of intervention, interpretation, and collaboration between the three academic researchers and the fourth author was chosen to increase the interpretive rigor of our analysis. In line with the research topic and the interpretive approach, our understanding of DPD in the game development project has come about through an iterative process of interpretation, comparison and connecting of prior research and empirical data which is in line with the fundamental principle of the hermeneutic circle. Applying the principle of contextualisation in this process as described in the introduction we took the social and historical background of the research setting into consideration and included it in the critical reflections of our case.

Given the distributed location of the project participants the extensive email trail between them was the main data source. Lee (1994) argues that email communication provides a rich understanding of what has occurred. These emails contained status information, reflections before, during and after the development and implementation of the game, conceptual 
feedback, reflections and recollections concerning input into the design of the game, the elements of climate change which it was addressing, test results as well as technical feedback. The empirical data also comprised social media postings by the four Fiji adolescents who served as facilitators between the technical development team and the juvenile Pacific Islander crowd and their responses to the request for input. Table 1 includes a list of all participants, their roles and their locations; more detail about the different actors, their relationship and their locations will be provided in the next section.

Project documentation such as the UNICEF (P) strategic plan for digital engagement, its project description, brief and evaluation as well as a terms of reference document were included as valuable data sources as were the field notes by the sponsor and the academic consultant. Further empirical data for the study was collected through semi-structured, openended interviews conducted by the academic consultant with the three members of the technical development team and by the outside researchers with the academic consultant and the project sponsor concerning their role and experiences during the project. The developers were interviewed for about 45 minutes in length with the interviews focusing on the issues around the DPD process and their reflections on the project. The issues included how they undertook the development process, how they managed the interactions with other participants, the mechanisms for communication and how they incorporated new ideas and change requests. The interviews also explored how the developers generated and refined their ideas particularly in relation to the sponsor's brief and delved into their motivations for becoming involved apart from the modest amount they were paid.

We wished to achieve an interaction between the existing literature and our observations from the case setting to explain interrelationships and contribute to theory with new insight from practice that might be useful for scholars and practitioners. In case study research identifying the boundaries of an investigated case is considered important (Miles et al. 2014). Our analysis takes its starting point in September 2010 when the project was conceived and ends in August 2011. Following with what Miles et al. (2014) describe as data condensation and based on Sarker et al. (2006) and our earlier work (Kautz 2009) our first step was to produce a list of the involved participants (see table 1), a timeline spanning that period (see figure 1) and a case narrative which is included in the following section in a condensed form. The narrative provides a progress or sequence of events and serves as a frame of reference for further analysis and interpretation of the data (Fincham 2002). The next stage involved revisiting the narrative and the empirical data as we then we mapped the data onto the CAS concepts and categorised our findings (see section 5) accordingly. Using CAS theory helped us to increase our understanding of DPD and ISD practice in the case setting. Before providing a more detailed analysis, we next present a narrative account of the investigated project. 


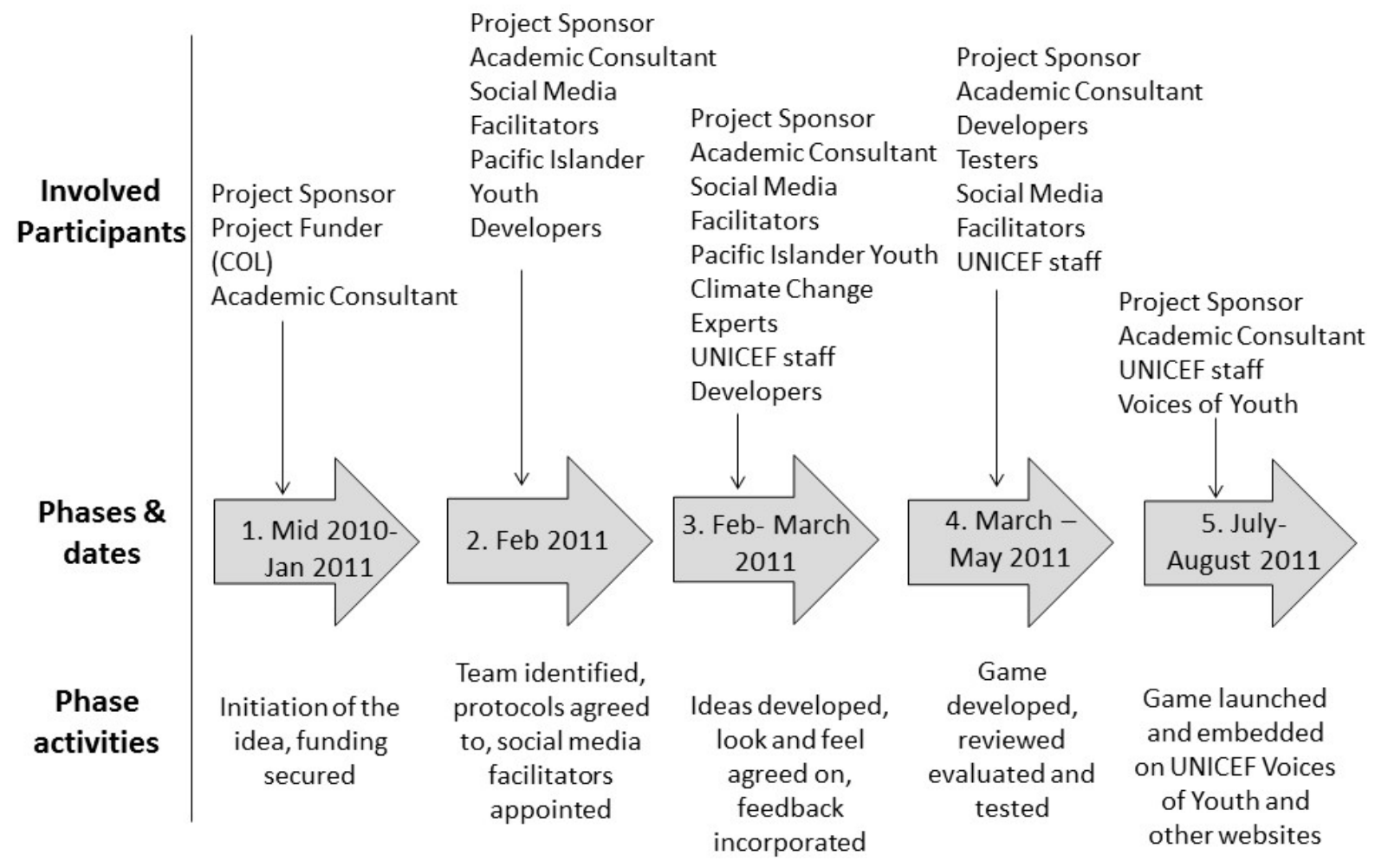

Figure 1. The Timeline of the Game Development Project

\section{A Case Narrative}

We identified the following five phases of the game development project: 1 Initiation of the idea and funding; 2 Establishment of the team; 3 Conceptual design of the game; 4 Development of the consolidated game; 5 Launch of the consolidated game.

\subsection{Phase 1 - Initiation of the idea and funding}

Mid 2010 the communications specialist at UNICEF (P) proposed a project to the organisation. He was concerned that although UNICEF $(\mathrm{P})$ had a strong social media presence and was regularly communicating with their audience via social media, two-way interaction was very limited. His major objective was to ensure that Pacific Islander youth engaged more with UNICEF. His vision was to engage youth through encouraging them to participate in a project via social media. Given the threats posed to small Pacific Islands from climate change the proposal was to develop a game which would also help youth to learn more about how to respond to climate change. He put this proposal to the Commonwealth of Learning (COL) in Canada, an intergovernmental organisation from the Commonwealth of Nation in November 2010 (for more information see www.col.org). The COL subsequently provided modest funding in early January 2011 for hiring developers. The communications specialist who was located on the Pacific Islands immediately approached an Information Systems professor in Melbourne, Australia who was known to him with a request to join the project as an involved, accompanying researcher in the role of an academic consultant to help establish, manage, and support, when need arises, a development team. This led to the second phase. 


\begin{tabular}{|l|l|l|}
\hline \multicolumn{1}{|c|}{ Project Participants } & \multicolumn{1}{c|}{ Roles } & \multicolumn{1}{c|}{ Locations } \\
\hline $\begin{array}{l}\text { UNICEF Communications } \\
\text { Specialist }\end{array}$ & $\begin{array}{l}\text { Project Sponsor, Project } \\
\text { Coordinator, Overall Decision } \\
\text { Maker }\end{array}$ & Fiji, Pacific Islands \\
\hline Information Systems Professor & $\begin{array}{l}\text { Involved Researcher as Academic } \\
\text { Consultant }\end{array}$ & Melbourne, Australia \\
\hline Three Research Students & $\begin{array}{l}\text { Developers in the Core } \\
\text { Development Team }\end{array}$ & $\begin{array}{l}\text { Hongkong, Melbourne, and } \\
\text { regional Victoria, Australia }\end{array}$ \\
\hline Four Fiji Adolescents & Social Media Facilitators & Fiji, Pacific Islands \\
\hline Pacific Islander Youth & Requirements Contributors & Pacific Islands \\
\hline Commonwealth of Learning (COL) & $\begin{array}{l}\text { Project Funder through Financial } \\
\text { Support }\end{array}$ & Canada \\
\hline UNICEF Staff & $\begin{array}{l}\text { Expertise Providers, Feedback } \\
\text { Providers, Functional and } \\
\text { Technical Testers }\end{array}$ & Pacific Islands, New York, USA \\
\hline Three Chinese Youth & Functional Testers & China \\
\hline International Climate Experts & Expertise Providers & Globally Distributed \\
\hline
\end{tabular}

Table 1. Project Participants, Roles, and Locations

\subsection{Phase 2 - Establishment of the team}

The academic consultant in January 2011 approached three young research students who fulfilled the position requirements; they accepted the invitation and were in the same month appointed as the developers for a period of 30 working days with an original project runtime from February 1 to April 15, 2011. Two of them were Chinese by birth and one was from Bangladesh. One developer was living in Hong Kong, another lived in regional Victoria, Australia and the third in Melbourne; the latter two knew each other, but they did not know the third developer beforehand, nor did they meet this developer in person during the project. The sponsor's first email to the development team including the academic consultant described his vision and what he wanted to achieve, the game was not to be about climate change but how people could respond to the impact of climate change. In January 2011, the sponsor identified and contacted four adolescents from Fiji to be social media facilitators for soliciting and gathering ideas from Pacific Islander youth about the game. The social media facilitators posted a photo with a message inviting input on the game and launched this as a Facebook album with text encouraging UNICEF (P) Facebook fans to participate and to contribute to the design of the game. Initial input and comments came from 16 fans, as well as 15 fans hitting the 'like' button.

During the same period the academic consultant facilitated a process among the members of the core development team and the sponsor who also acted as project co-ordinator where protocols for how the development team would operate were agreed. The academic consultant played no further significant role in the development process after the communication protocols had been agreed, but as stated above provided occasional advice and observed the course of the project. The sponsor was happy for the developers to manage the project themselves in terms of ideas for the game and how the work was undertaken. The developers' first meeting was a telephone conversation about how they would manage the process given they were geographically dispersed. They agreed that they would email each other every couple of days to cater for the quite short timeline for finalising the game. They also decided to use Skype to talk and instant messaging and chat to communicate. Although there was no formal team leader, the student from Bangladesh very quickly took charge of managing how 
things would work, she kept meeting minutes including the decisions that were taken, the next discussion topics and who would be responsible for determining what the tasks would be. The tasks were reviewed at each meeting confirming what had been done and establishing the next tasks and responsibilities. At the end of each meeting an email summarising progress was sent to the sponsor by the informal leader. He reviewed the progress and if he thought there was something that needed to be changed or wanted to provide feedback, he would email the informal leader or alternatively he called her using Skype. Brief notes were taken from the Skype meetings focusing on any requested changes.

\subsection{Phase 3-Conceptual design of the game}

The first stage of development was to reach agreement on what the game would be and its look and feel. One developer researched relevant aspects of climate change, another looked at different approaches to and types of Facebook games and the third investigated appropriate technologies, tools and development approaches. As the development of the ideas for the game progressed the sponsor was an intermediary sharing these ideas with a range of people from the funding organisation, climate change experts and UNICEF staff to receive input concerning the direction of the game. Further information on climate change was also provided on a regular basis by the relevant experts to the sponsor. The sponsor handed the feedback and the ideas of the involved Pacific Islander youth provided through the Facebook page and facilitated by the four adolescents from Fiji to the developers. The requirements of the sponsor and ideas of the key stakeholders, Pacific Islander youth, and UNICEF staff, guided the developers. The team used the following process to decide on their final game: At the very beginning the sponsor asked the developers to think about some ideas. They gave themselves a week to brainstorm and then collected their ideas to see which of them could be combined. This led to three major ideas; each with a particular focus from one developer which reflected what they individually thought what the youth and UNICEF (P) should concentrate on. This resulted in a game which consisted of three games in one (see figure 2). Each game was quite different in the way the players would interact; the $\mathrm{CO} 2$ Reducer challenge requires players to identify potential $\mathrm{CO} 2$ emitters; the Evacuate Life challenge requires players to understand the climate change threats and initiate action, e.g. to evacuate or rebuild before there are serious consequences; the Flood Tales challenge highlights the causes of floods and the need for flood mitigation. An important design principle was to ensure that each game was not too complicated. The developers found the fan page postings very helpful; the responses from the Pacific Islander youth had suggested that the game needed to be very interactive, interesting and colourful; it should have graphics, be fun and focused on action, something which promoted to be positive and to make change.

\subsection{Phase 4 - Development of the consolidated games}

After the developers and the sponsor had agreed on the consolidated game's design, development proper, including detailed design, coding, testing and evaluation could begin. Concerning the management and coordination of the process, one developer commented: "[The development process proper] was very challenging because we would not face each other and sit together, this was a challenging part." The team took an active role in ensuring input in the form of further information and feedback was managed effectively and encouraged further participation by the sponsor and UNICEF (P) staff. As there was no opportunity to discuss, elaborate and clarify ideas and concerns face to face all information and communication had to be, and eventually was, very concise. As the team members were working independently 
and each component of the game was developed separately, several issues concerning the build and layout of the consolidated game arose during this phase as one developer highlighted: "The game came in three different formats, totally different interfaces. The developing process of the three people was quite different. It came as three totally different styles of game, different user interface, different colour, a lot of things were different. There was no standard look to the three different games. Fortunately, finally we got this sorted out - the three games now look quite similar."

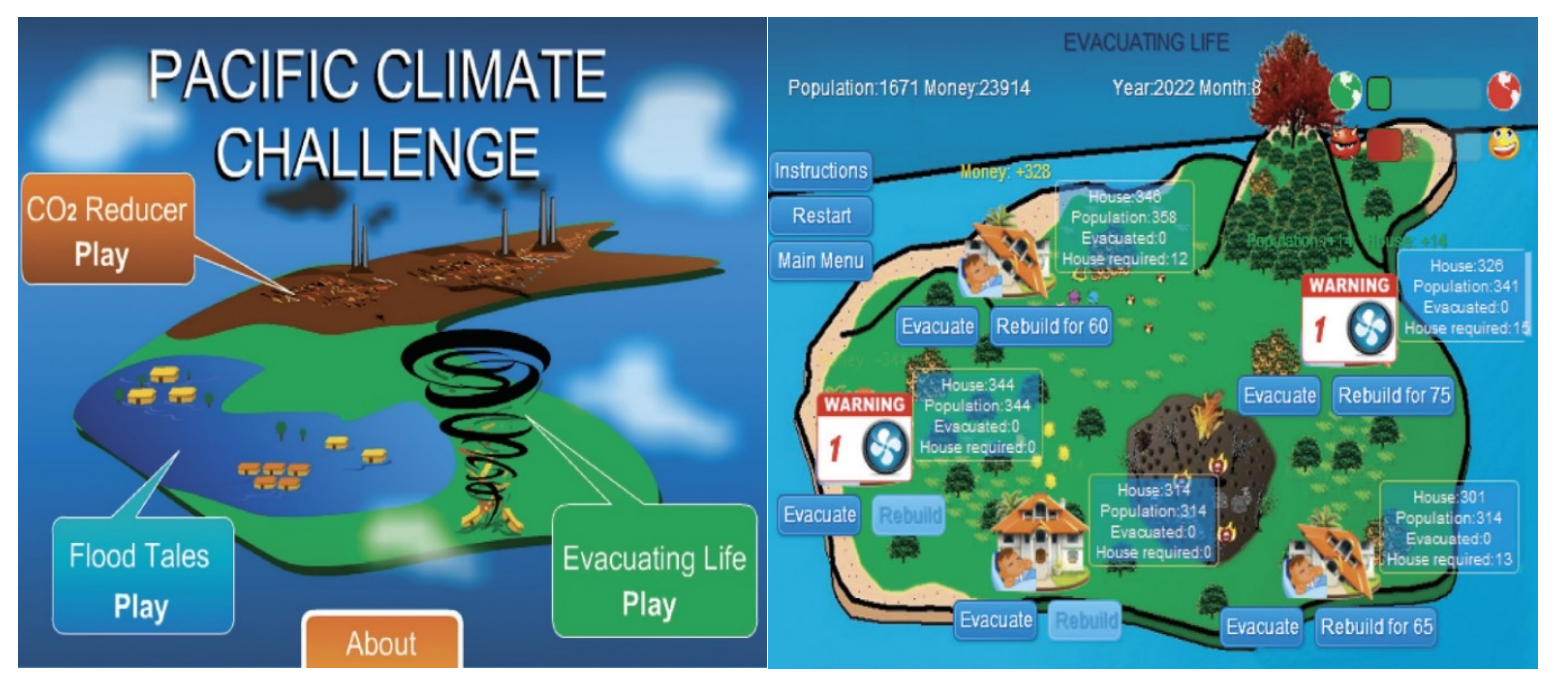

Figure 2: An Illustration of the Games (adopted from Fisher 2012)

The sponsor and UNICEF $(\mathrm{P})$ staff reviewed the first version of the consolidated game and provided feedback; this included the colours, fonts and graphics, the text and help function provided with the game. The sponsor highlighted that further work was needed on standardisation and how the three components linked together to be one game. The sponsor also reinforced the need for links to further information be embedded in each game. Technical testing and evaluation were iterative. The developers each first conducted technical unit and system testing to uncover programming errors and for this purpose identified a set of criteria in particular to test the features of the game, to ensure the various games linked internally, that the colour schemes, text size and files et cetera were correct and consistent. Each developer tested the work of the other two and provided feedback through their regular phone and Skype meetings and email. While the developers tested for programming errors the game was functionally tested by UNICEF (P) staff who played the game and provided feedback to the sponsor. A technical person within UNICEF also tested the consolidated game and provided technical feedback once the team had incorporated the earlier feedback. The developers were also asked to find a platform to run the game and after investigation identified Google which had a free service. Further user evaluation similar to user acceptance testing was undertaken by three friends of the developers in China who were young and used Facebook. They played the game and provided advice suggesting that the graphics and artwork needed to be still more attractive. They thought players would be encouraged to play longer if the game was even more interesting. The social media facilitators also provided feedback along these lines, suggesting the game be more colourful and easier to play. All feedback was considered, further changes made, and the final version of the game was ultimately accepted by the sponsor. 


\subsection{Phase 5 - Launch of the consolidated game}

An email to various international UNICEF groups announced the launch of the game in July 2011. The game had a favourable reception as many positive comments on what had been achieved were made by UNICEF worldwide, Pacific Islander youth and Facebook fans. A press release issued shortly after the launch showed UNICEF's positive assessment of the initiative. Postings on the UNICEF ( $P$ ) fan page highlighted how successful the game was with requests for the game to be translated into Pacific Islands' languages and to include it on the Madagascar UNICEF page. Voices of Youth, a UNICEF organisation designed to support young people and to give them the opportunity to learn about their world requested that they embed the game on their website which the developers then did. Lastly, the launch event marked the end of the project for the development team and sparked the developers' pride about their achievement. The consolidated game is now in use and distributed through three Facebook sites: UNICEF (P), Voices of Youth and Unite for Climate.

\section{Analysis and Discussion: The Game Development Project as a Complex Adaptive System}

The DPD in the game development project can be analysed and discussed from many theoretical perspectives. Such perspectives could be the low degree of IT use, notably of social media, by intergovernmental, non-governmental or not-for-profit organisations (Chang and Chang 2011; Cokerill 2013), their challenges of engagement with youth (Henderson and Bowley 2010) and of the empowerment of this specific user group (Clement 1994), markedly through gamification (Hamari et al. 2014); another focus could be to examine the project as a particular instance of open source software development (Titlestad et al. 2009) or to take the general discourse on crowdsourcing (Lukyanenko et al. 2016) or on crowdsourcing in ISD for value co-creation (Kazman and Chen 2009) into account as we have done elsewhere (Kautz et al. 2019). Our focus here however is on DPD as an approach to ISD and how DPD projects in crowdsourced ISD unfold and are managed and performed in their entirety. As contemporary ISD is generally acknowledged as a complex activity we apply complex adaptive systems (CAS) theory to better understand and make recommendations for ISD practice. Benbya and McKelvey (2006) based on conceptual work, Meso and Jain (2006) with support from examples from the literature, and Vidgen and Wang (2009) backed up through an empirical case, all focus on certain CAS concepts for the organisation of ISD projects, mostly agile development, without any consideration of distributed activities. The same is valid for Kautz (2012) whose research went beyond agile development but stayed within the boundaries of a nondistributed project organisation. Our work is based on these predecessors but centred around the idea of emergence we chose for our analysis of a distributed development endeavour a set of interrelated concepts that characterize CAS: interaction, interconnected autonomous agents, self-organisation, poise at the edge of chaos, co-evolution, time pacing, and poise at the edge of time.

\subsection{Interactions}

Interactions are a significant characteristic of a complex adaptive system. Based on the initial project organisation which had been established by the sponsor with support from the academic consultant and which consisted of a first project plan and vision, an early requirements specification, and a formal contract for the developers and continuing with the enrolment of various other participant groups and emerging organisational structures, 
interactions in the DPD and crowdsourced game development project took mainly place through various digital technologies and involved the different participant groups throughout the whole project in multiple forms, formal and informal, and at numerous occasions organised and spontaneous. They could among others be found during the scheduled meetings and feedback sessions between the sponsor and the developers and between the developers themselves. The narrative of the case which describes the project participants and their roles and relationships provides ample evidence of the rich, intense, dynamic, and nonlinear interactions which were fed back into the project and determined its performance and its emerging innovative properties resulting in the consolidated game. It indicates that project's progression could not be predicted. The difference between the planned three months for developing the game and the actual seven months illustrates this and the concept of emergence describes this characteristic of CAS. In the following, we revisit the game development project and accentuate the different facets of emergence and of the other key concepts of CAS theory to provide a better understanding of DPD in crowdsourced ISD and to derive some insights for the organisation of such ISD projects. Our analysis shows how all these core concepts of CAS are strongly entwined and reciprocally reinforce each other. Table 2 contains, as a summary of our findings, the CAS concepts, their characteristics and the emerging effects in the game development project.

\begin{tabular}{|c|c|c|}
\hline CAS Concept & CAS Characteristics in the project & Emerging Effect \\
\hline Interaction & $\begin{array}{l}\text { Multiple forms of interaction: formal \& } \\
\text { informal, organised \& spontaneous, at } \\
\text { numerous occasions, among others during the } \\
\text { scheduled meetings \& feedback sessions } \\
\text { between the various participant groups, } \\
\text { through mainly digital technologies }\end{array}$ & $\begin{array}{l}\text { Unpredictable, rich, intense, dynamic, } \\
\text { non-linear interactions fed back into the } \\
\text { project \& determined its performance \& } \\
\text { emerging innovative properties of the } \\
\text { resulting consolidated game }\end{array}$ \\
\hline $\begin{array}{l}\text { Inter- } \\
\text { connected, } \\
\text { Autonomous } \\
\text { Agents }\end{array}$ & $\begin{array}{l}\text { Interconnected, autonomous agents in } \\
\text { distributed groups of participants organised in } \\
\text { a kernel, periphery \& as masses; } \\
\text { sponsor and facilitators as social mechanisms } \\
\text { coordinated by simple rules, digital } \\
\text { technologies as technical mechanisms; } \\
\text { developer autonomy when distributing \& } \\
\text { selecting tasks \& manifested in their individual, } \\
\text { autonomous design decisions contributions; } \\
\text { social media facilitator autonomy when } \\
\text { filtering requirements; } \\
\text { autonomy at the periphery \& in the masses } \\
\text { when participants joined \& left as they saw fit }\end{array}$ & $\begin{array}{l}\text { Sharing of project-relevant knowledge } \\
\text { in feedback sessions \& meetings; } \\
\text { all kernel members' involvement in } \\
\text { project management \& design } \\
\text { decisions; } \\
\text { developers' task self-assignment; } \\
\text { involvement of other participants in } \\
\text { design and evaluation activities; } \\
\text { emergence of collective learning among } \\
\text { these participants }\end{array}$ \\
\hline $\begin{array}{l}\text { Emergent } \\
\text { Self-Organisation }\end{array}$ & $\begin{array}{l}\text { Emergent self-organisation: through egalitarian } \\
\text { management with short communication paths; } \\
\text { sponsor \& facilitators acted like peers; } \\
\text { developer self-organisation through shared } \\
\text { responsibility for governance/decision making, } \\
\text { task self-assignment, self-appointed team } \\
\text { manager; } \\
\text { social media facilitator self-organisation } \\
\text { through the way requirements \& feedback were } \\
\text { solicited \& filtered }\end{array}$ & $\begin{array}{l}\text { Emergence of self-organisation of } \\
\text { autonomous project members, in } \\
\text { particular developers \& social media } \\
\text { facilitators; } \\
\text { emergence of order with individual \& } \\
\text { team discipline as vital elements of self- } \\
\text { organisation }\end{array}$ \\
\hline
\end{tabular}




\begin{tabular}{|c|c|c|}
\hline CAS Concept & CAS Characteristics in the project & Emerging Effect \\
\hline $\begin{array}{l}\text { Poise at the } \\
\text { Edge of Chaos }\end{array}$ & $\begin{array}{l}\text { State of bounded instability: stability through } \\
\text { initial project plan \& vision, overall } \\
\text { requirements specification, formal contract, } \\
\text { organisation of participants in kernel; } \\
\text { instability through different participant groups } \\
\text { spread over continents/time zones \& } \\
\text { continuous flow of ideas, requirements, change } \\
\text { requests, feedback; } \\
\text { balanced by emergent organisation in stable } \\
\text { kernel, dispersed periphery \& independent } \\
\text { masses }\end{array}$ & $\begin{array}{l}\text { Appearance of a region of emergent } \\
\text { complexity with steady, swift handling } \\
\text { of frequently incoming input through } \\
\text { short iterations of manageable size \& } \\
\text { regular planning/feedback sessions in } \\
\text { the kernel }\end{array}$ \\
\hline $\begin{array}{l}\text { Emergent } \\
\text { Co-evolution }\end{array}$ & $\begin{array}{l}\text { Co-evolution of people, processes, products } \\
\text { through multiple forms of interactions, } \\
\text { knowledge sharing \& mutual learning about } \\
\text { ideas, requests, early game versions \& feedback }\end{array}$ & $\begin{array}{l}\text { Reinforcement of emergent structures } \\
\text { of interaction \& collaboration \& } \\
\text { unpredictable emerging structures \& } \\
\text { behaviours through unplanned } \\
\text { inclusion/departure of participants } \\
\text { resulting in changes of the game }\end{array}$ \\
\hline Time Pacing & $\begin{array}{l}\text { Time pacing: internally set through short } \\
\text { iterations, early test versions, as well formal } \\
\text { weekly \& regular within a week planning } \\
\text { meetings/feedback sessions, based on rules for } \\
\text { coordination \& engagement; } \\
\text { mechanisms for selecting ideas, requests, } \\
\text { requirements; manageable requirements size }\end{array}$ & $\begin{array}{l}\text { Emergence of a working rhythm with } \\
\text { appropriate intervals to handle changes } \\
\text { resulting in changes in the game not } \\
\text { occurring too frequently \& too fast }\end{array}$ \\
\hline $\begin{array}{l}\text { Poise at the Edge } \\
\text { of Time }\end{array}$ & $\begin{array}{l}\text { Poise at the edge of time: focus on present } \\
\text { through attention on current iteration, } \\
\text { requirements \& design proposals taking into } \\
\text { account existing version \& design of future } \\
\text { extensions; } \\
\text { focus on past \& future through overall project } \\
\text { plan, project vision, frequent planning/feedback } \\
\text { sessions; } \\
\text { focus on present \& future by sponsor \& } \\
\text { developers reflecting on development process }\end{array}$ & $\begin{array}{l}\text { Emergent balance of exploitation \& } \\
\text { exploration manifested in current } \\
\text { versions of the game, the consolidated } \\
\text { game with standardised interface, } \\
\text { developed formats for management \& } \\
\text { communication, inclusion of further } \\
\text { projects participants in testing \& } \\
\text { evaluations activities }\end{array}$ \\
\hline
\end{tabular}

Table 2: CAS Characteristics of the game development project

\subsection{Interconnected, Autonomous Agents and the Emergence of Team Learning}

In the game development project, all participants acted as autonomous, interconnected agents. The different distributed groups of participants were interconnected through various social and technical mechanisms. Technologies, mostly digital ones, such as telephone, email, Skype, instant messaging and chat were mainly used to connect in what Kazman and Chen (2009) call the kernel of a crowdsourced project, while email and primarily Facebook were used in the periphery and by the masses in the crowd (Kazman and Chen 2009). The sponsor and the social media facilitators acted as social mechanisms and implemented simple rules of engagement to coordinate design proposals and other input from the periphery and the masses. The sponsor and the developers had developed another simple set of rules for the communication between them and within the development team. The participants' autonomy was expressed in numerous ways. At the periphery the Pacific Islander youth requirements contributors, the various UNICEF staff as well as the testers voluntarily joined the project, provided their input, and left the project as they saw fit. The social media facilitators 
autonomously communicated with the requirements contributors and filtered their input for the sponsor and the developers. The autonomy of the developers showed when they contributed to the functional design where the sponsor then made the final decisions. Their autonomy became even more apparent in the liberty that the developers had when distributing and picking tasks. Further, when implementing the games, the developers acted as self-governing with regard to the technical design decisions they made. Despite that autonomy, the project participants were highly interlinked and maintained their relationships through the above described structures and measures, which supported the various described forms of interactions to achieve interconnectivity. A result of autonomy, the different capabilities of autonomous, interconnected agents and their interactions is the emergence of team learning (Mitleton-Kelly 2003). The sharing of project-relevant knowledge in the scheduled feedback sessions and frequent meetings, combined with all the kernel team members' involvement in project management and design decisions, in addition to the developers' self-assignment of tasks based on competence and interest, led to the emergence of collective learning among the participants in the kernel of the project. They also learned about the crowdsourced development and utilization of digital games and the issue at hand, climate change. Through the involvement of other participants in design and evaluation activities the emergent learning spread to, and in, these other involved groups of participants as well.

\subsection{Emergent Self-Organisation and the Emergence of Order}

The concept of self-organisation departs from the command and control philosophy of traditional organisations. It places emphasis on increased autonomy, delegated decision making, more interactions with other individuals and the environment. Individuals and teams must still define and follow local rules and allow these rules to evolve over time in the course of self-organisation. Self-organisation is closely related to the concept of interconnected, autonomous agents (Volberda and Levin 2003). The game development project showed all these characteristics. The project was not led and controlled top-down but managed in a rather egalitarian manner. The sponsor acted primarily as a facilitator and co-ordinator. After having negotiated the communication protocol with the developers and the social media facilitators he created an environment with short communication paths that fostered self-organisation of the developers which was characterised by task self-assignment and largely autonomous decision making and joint responsibility. One of them, self-appointed and accepted by the other two, co-ordinated their work internally in their team. In fact, all those in facilitator roles appeared more like peers and were part of a very flat organisational structure as they contributed to the environment that nurtured self-organisation. Self-organisation was further evidenced by the way the social media facilitators solicited and filtered the requirements which were provided by the other youth, and the way these youth offered their ideas. The implementation of the communication protocols and the introduction of the role of the social media facilitators illustrate the emergence of self-organisation of autonomous participants and the subsequent emergence of order in the design and development process of the project. It also shows that individual and team discipline are not in conflict with, but a vital element of, self-organisation. In this context, the way feedback - beyond the self-organised regular feedback sessions - was provided and gathered from the other participants and subsequently handled in orderly form, as part of planning activities, also reflects the emergence of order. 


\subsection{Poise at the Edge of Chaos and the Region of Emergent Complexity}

The game development project poised at the edge of chaos as it was constantly in a state of bounded instability which means that it, paradoxically, was simultaneously stable and unstable (Stacey 2003). The sponsor's initial project plan and vision as well as his specification of the overall requirements, the developers' formal contract, and the organisation of a kernel consisting of the sponsor and the developers, acted as super-ordinate structuring mechanisms that created a relative stable space within which the development process and the various versions of the game could unfold. However, it also had to deal with the instability brought about by the continuous flow of ideas, requirements, change requests, and feedback caused by the involvement of the different participant groups which were spread over several continents and time zones. These made up the edge of chaos where complexity emerged. The project balanced this complexity and coped with the 'chaos' (Benbya and McKelvey 2006) by emergent organisation of the participants in (1) the before mentioned separate stable kernel which had a decision mandate and performed the functional and technical design as well as the technical development tasks, (2) a dispersed periphery which provided, facilitated and filtered requirements and feedback and (3) independent and even less stable masses who provided ideas and requirements. This organisational form allowed for the steady and flexible handling of, and swift reaction on the frequently incoming input through short iterations of manageable task size, as well as through the regular planning and feedback sessions of the participants in the kernel of the project. It illustrates how the project manoeuvred in a region of emergent complexity, and balanced at the edge of chaos as these measures at the same time supported the necessary flexibility and provided a frame for stability, as they structured the project participants' activities and helped those in the kernel to know what to do, when to do it, and what to expect from others.

\subsection{Emergent Co-evolution and the Emergence of Behaviour and Structure}

Co-evolution emerged in the game development project through the above described multiple forms of interactions in which the distributed participants shared knowledge and learned from each other. The mutual learning had the reciprocal effect of reinforcing the emerging structures of collaboration and interaction, as well as the behaviour of the individual project participants. In particular, the continuous provision, filtering, and handling of ideas, requests, requirements, and other feedback, along with the frequent availability of early versions of the game fuelled this process. It kept the participants informed about the current status of the game and provided opportunities to explore, evaluate, and learn how to use it, as well as to create new ideas that were then fed back to the development team to become part of the next version. Thus, the game co-evolved with the distributed participants. Together, this demonstrates the co-evolution of people, processes and products (Meso and Jain 2006). The project also exhibited the unpredictable emergent behaviour and structure of the different entities of a CAS based on the described co-evolution during the distributed design and development process. The organisational structure of the dispersed participants was not planned on beforehand nor was the inclusion of certain participants. The youth requirement contributors, the UNICEF staff and the climate experts joined the project voluntarily when being called upon and left it when they had decided to do so without any notice; they were largely unknown to each other and the other participants. Further, the idea of involving other young people such as the testers or the requirements contributors in further feedback cycles on the design and early versions of the game emerged during the developers' interactions. When implemented, the feedback changed the game and its behaviour accordingly. 


\subsection{Time Pacing and the Emergence of Rhythm}

In the game development project, the overall project plan and the developers' contract set the time frame for the DPD and development process. The short iterations made early versions of the games available. The emergence of a lasting working rhythm and the setting of the pace for the project were supported by the virtual planning meetings and feedback sessions, held weekly or more often, that handled the continuously incoming input from the participants at the periphery and the masses. This was achieved through the agreed rules for coordination, communication, and engagement, as well as mechanisms for selecting the ideas, requests, and requirements from the different dispersed participants. As a result, the versions of the game did not change too frequently or too fast. Together with the manageable size of the requirements, it provided the appropriate intervals to match and handle the changes. In this way, time pacing, as reported by Vidgen and Wang (2009) and the emerging internal rhythm drove change in the project in accordance with the passage of time and, at the same time, allowed for stability and flexibility.

\subsection{Poise at the Edge of Time and the Emergent Balance of Exploitation and Exploration}

In CAS theory a focus on the present while keeping the past in mind and preparing for the future is regarded as poising at the edge of time (Brown and Eisenhardt 1998). In the game development project, the centre of attention was always the current iteration and the current requirements and design proposals while also taking into account the existing version of the game and the design for future extensions. The developers built the game through several iterations where they at any point took the available knowledge and requirements concerning the development process, the game development, and the issue at hand, climate change into consideration, while investigating further options, receiving new ideas, requirements and feedback. The developers exploited existing knowledge by including links to other information resources, by using accessible code from other games, and not least by sharing code between themselves. They used ideas, requirements and proposals with their roots in the presence and simultaneous awareness of the past and the future approved by the sponsor to produce a current version of the game whilst investigating prospective options with information and feedback from, and in consultation with, the sponsor, but also the social media facilitators, the youth requirements contributors, local and headquarter UNICEF staff, international climate change experts, and the three testers. In doing so the project concurrently balanced the exploitation of existing knowledge and the exploration of new knowledge at the edge of time (Bocanet and Ponsiglione 2012). This emerging balance was supported through the frequent virtual meetings and feedback sessions between the developers themselves and between them and the sponsor as well as the other coordination and filtering mechanisms. The overall project plan and vision, as well as the frequent planning sessions structured around 'releases' and iterations of current versions of the game, supported a focus on, and constituted a manifestation of, both the past and the future. The frequent feedback sessions with the sponsor were also used by the developers to think about their own behaviour and to review and improve the development process. This is reflected in the developed formats for management and communication in the core team, the consolidated game with a standardised interface as well as the inclusions of further youth into the distributed testing and evaluations activities. 


\section{Conclusion}

Prior research into PD centred to a large extent on industrial environments with a focal organisation with some exceptions notably in open source software development in the notfor-profit arena (Kazman and Chen 2009; Lukyanenko et al. 2016). Most of the work on DPD is based on action research projects with significant intervention by researchers and only to a lesser extent on actual empirical practice studies without or only marginal direct influence by a research team on the course of the DPD project; DPD research also focusses heavily on individual methods, techniques, and practices (Gumm et al. 2006; Obendorf et al. 2009; Titlestad et al. 2009; Näkki and Koskela-Huotari 2012; Lukyanenko et al. 2016). In contrast, ours is a case study of genuine DPD through an intergovernmental, not-for-profit organisation - an organisation that is neither a part of a government nor a conventional for-profit business - and mainly youth in an ISD project of a digital game. Our analysis provides an in-depth understanding of how the project was managed and performed in its entirety in a not-forprofit environment. It reveals a complex network of geographically dispersed actors in a transient project organisation.

We demonstrate that the game development project can be understood as an example of DPD in contemporary, crowdsourced ISD. Furthermore, by applying CAS theory we show that the project can be understood as a CAS and that CAS theory provides explanations for how and why DPD as an approach to contemporary ISD worked in the investigated case. The validation of our empirical results through the application of CAS theory contributes to the growing literature that acknowledges CAS theory as a relevant theoretical foundation for understanding contemporary DPD and ISD. Researchers can use CAS theory to perform, analyse, present and compare longitudinal case studies of how DPD, and more general ISD unfolds in practice over time. This is crucial as social science and IS researchers (see e.g. Eisenhardt 1989; Walsham 1995; Van de Ven 2007) highlight that the complexity of practice is such that a theory and an explicit framework of ideas are necessary as a guide for data collection and identification of important research findings. Detailed studies of practice and subsequent formulation of empirically grounded theories serve to enhance researchers and practitioners' knowledge and to introduce new concepts that both groups can bring to their respective practice (Madsen et al. 2006).

Our work has practical bearings, too. It shows how actual DPD can be organised in a project to result in a process and outcome that all stakeholder groups appreciate. In practice, while recognising that the actual course of an ISD project will evolve with the situation, CAS can be used for: (1) managing and performing DPD during the development process by providing an understanding of DPD as an approach to ISD, and (2) after-the-fact reflection and collection of lessons learnt.

In conclusion, we acknowledge that our study is an exploratory, single case study and that the game development project belongs to a special class of development project which may limit the generality of our findings. But, like Walsham (1995) and Klein and Myers (1999), we contend that this does not mean that it does not contribute to - in our case a sound empirical practice study and rich insight about DPD as a vital approach to ISD - the collective body of knowledge, both academic and practical, of a discipline. While our research provides a link between the otherwise often disconnected research areas and research communities of DPD, ISD and CAS, still more studies are necessary to allow for more theorising and for a viable theory of DPD in ISD. To accomplish a more exhaustive explanatory theory, to answer why 
DPD in ISD played out the way it did in the presented case and to draw more general lessons learnt, further research is needed.

\section{References}

Alvesson, M., and Sandberg, J. 2011. “Generating Research Questions through Problematization," Academy of Management Review (36:2), pp. 247-271.

Alvesson, M., and Sandberg, J. 2013. “Has Management Studies Lost Its Way? Ideas for More Imaginative and Innovative Research," Journal of Management Studies (50), pp. 128-152.

Anderson, P. 1999. “Complexity Theory and Organization Science," Organization Science (10:3), pp. 216-232.

Baiyere, A. 2017. "The Interface of IT Capabilities and Disruptive Innovation," in Proceedings of the $28^{\text {th }}$ Australasian Conference on Information Systems (ACIS 2017), Hobart, Tas, Australia, December 4 - 6, 2017.

Benbya, H., and McKelvey, B. 2006. "Toward a complexity theory of information systems development," Information Technology E People (19:1), pp. 12-34.

Boell, S. K., and Cecez-Kecmanovic, D. 2014. "A Hermeneutic Approach for Conducting Literature Reviews and Literature Searches," Communications of the Association for Information Systems (34), article 12.

Brown, S., and Eisenhardt, K. 1998. Competing on the Edge: Strategy as Structured Chaos, Boston, MA: Harvard Business School Press.

Bocanet, A., and Ponsiglione, C. 2012. "Balancing exploration and exploitation in complex environments," VINE - The Journal of Information and Knowledge Management Systems (42:1), pp. 15-35.

Chang, Y.-J., and Chang, Y.-S. 2011. "Investigation of Organizational Interaction and Support in an NGO through Computer-Mediated Discussions," Journal of Educational Technology E Society (14:3), pp. 130-140.

Cilliers, P. 2000. “What Can We Learn From a Theory of Complexity?” Emergence (2:1), pp. 2333.

Clement, A. 1994. "Computing at Work: Empowering Action By 'Low-level Users'," Communications of the ACM (37:1), pp. 52-63.

Clement, A., Costantino, T., Kurtz, D., and Tissenbaum, M. 2008. "Participatory design and web 2.0: the case of PIPWatch, the collaborative privacy toolbar," in Proceedings of the $10^{\text {th }}$ Conference on Participatory Design, Bloomington, IN, USA, ACM, pp. 51-60.

Cockerill, C.H. 2013. "Exploring Social Media Obstacles and Opportunities within Public Agencies: Lessons from the Ohio Division of Wildlife," International Journal of Business and Social Science (4:2), pp. 39-44.

Creswell, J. 2003. Research design - Qualitative, quantitative and mixed methods approaches, Thousand Oak, CA: Sage Publications.

DiSalvo, C., Clement, A., and Pipek, V. 2013. Communities: Participatory Design for, with and by communities. In J. Simonsen and T. Robertson, T. (eds.), Routledge International Handbook of Participatory Design, NY: Routledge, pp. 218-248. 
DiSalvo, B., and DiSalvo, C. 2014. "Designing for Democracy in Education: Participatory Design and the Learning Sciences," in Proceedings of the 11 $11^{\text {th }}$ International Conference of the Learning Sciences, Boulder, CL, USA.

Eisenhardt, K. 1989. "Building Theories from Case Study Research," The Academy of Management Review (14:4), pp. 532-550.

Fincham, R. 2002. “Narratives of Success and Failure in Systems Development," British Journal Management (13), pp. 1-14.

Fisher, J. 2012. “Engaging Pacific youth through a Facebook game," ACM Inroads (3:4), pp.7985.

Gerring, J. 2007. Case Study Research: Principles and Practices, Cambridge: Cambridge University Press.

Ghazawneh, A., and Henfridsson, O. 2013. “Balancing Platform Control And External Contribution In Third-Party Development: The Boundary Resources Model," Information Systems Journal (23:2), pp. 173-192.

Gumm, D.C., Janneck, M., and Finck, M. 2006. “Distributed participatory design - a case study," in Proceedings of the NordiChi Workshop on Distributed Participatory Design, Vol. 2, Oslo, Norway.

Hamari, J., Koivisto, J., and Sarsa, H. 2014. "Does gamification work? - A literature review of empirical studies on gamification," Paper presented at the 47th Annual Hawaii International Conference on System Sciences.

Henderson, A., and Bowley, R. 2010. "Authentic dialogue? The role of "friendship" in a social media recruitment campaign," Journal of Communication Management (14:3), 237-257.

Highsmith, J. 2000. Adaptive Software Development: A Collaborative Approach to Managing Complex Systems, NY: Dorset House Publishing.

Highsmith, J. 2002. Agile Software Development Ecosystems, Boston, MA: Addison-Wesley.

Holland, J. H. 1995. Hidden Order: How Adaptation Builds Complexity, Reading, MA: AddisonWesley.

Holland, J. H. 1998. Emergence: From Chaos to Order, Cambridge, MA: Perseus Publishing.

Jacucci, E., Hanseth, O., and Lyytinen, K. 2006. "Taking complexity seriously in is research. Introduction to the Special Issue," Information Technology \& People (19:1), pp. 5-11.

Jain, R., and Meso, P. 2004. "Theory of Complex Adaptive Systems and Agile Software Development," in Proceedings of the $10^{\text {th }}$ Americas Conference on Information Systems, New York, NY, pp. 1661-1668.

Kanuha, V. K. 2000. “"Being native" versus "going native": Conducting social work research as an Insider," Social Work in Health Care (45:5), pp. 439-447.

Kauffman, S. 1993. The Origins of Order: Self-Organisation and Selection in Evolution, NY: Oxford University Press.

Kautz, K. 2009. “Improvisation in Information Systems Development Practice," Journal of Information Technology Case and Application Research (11:4), pp. 30-59. 
Kautz, K. 2012. "Beyond Simple Classifications: Contemporary Information Systems Development Projects as Complex Adaptive Systems," in Proceedings of the 33rd International Conference on Information Systems, Orlando, FL.

Kautz, K., and Madsen, S. 2010. "Understanding Agile Software Development in Practice," in Proceedings of the 2010 International Conference on Information Resources Management, Rose Bay, Jamaica.

Kautz, K., Bjerknes, G., Fisher, J., and Jensen, T. 2019. “The Process of Co-creation in Information Systems Development: A Case Study of a Digital Game Development Project," in Andersson, B. et al. (eds), Advances in Information Systems Development: Designing Digitalization, Lecture Notes in Information Systems and Organisation, Springer Publishing Company, Cham, Switzerland, Vol. 34, pp .187-206.

Kazman, R., and Chen, H. 2009. "The metropolis model a new logic for development of crowdsourced systems," Communications of the ACM (52:7), pp. 76-84.

Kelly, K. 1994. Out of Control - The New Biology of Machines, Social Systems, and the Economic World, New York, NY: Addison-Wesley.

Kensing, F., and Blomberg, J. 1998. "Participatory Design: Issues and Concerns," Computer Supported Cooperative Work (7:3), pp. 167-185.

Klein, H., Myers, M.D. 1999. "A Set of Principles for Conducting and Evaluating Interpretive Field Studies in Information Systems," MIS Quarterly (23:1), pp. 67-93.

Lee, A. S. 1994. “Electronic Mail as a Medium for Rich Communication: An Empirical Investigation Using Hermeneutic Interpretation," MIS Quarterly (18:2), pp. 143-157.

Lukyanenko, R., Parsons, J., Wiersma, Y. F., Sieber, R., and Maddah, M. 2016. “Participatory Design for User-generated Content: Understanding the challenges and moving forward," Scandinavian Journal of Information Systems (28:1), pp. 37-70.

Madsen, S., Kautz, K., and Vidgen, R. 2006. “A framework for understanding how a unique and local IS development method emerges in practice," European Journal of Information Systems (15:2), pp. 225-235.

Markus, M. L., and Mao, J.-Y. 2004. "Participation in development and implementationupdating an old, tired concept for today's IS contexts," Journal of the Association for Information Systems (5:11), pp. 515-544.

McMillan, E. 2004. Complexity, Organizations, and Change, London, UK: Routledge.

Merali, Y., and McKelvey, B. 2006. "Using complexity science to effect a paradigm shift in information systems for the 21st century," Journal of Information Technology (21:4), pp. 211-215.

Meso, P., and Jain, R. 2006. “Agile Software Development: Adaptive Systems Principles and Best Practices," Information Systems Management (23:3), pp.19-30.

Miles, M. B., Huberman, M. A., and Saldana, J. (2014). Qualitative Data Analysis (3 ${ }^{\text {rd }}$ ed.), London: Sage.

Mitleton-Kelly, E. 2003. “Ten principles of complexity and enabling infrastructures," in Mitleton-Kelly, E. (ed.), Complex systems and evolutionary perspectives on organisations: the application of complexity theory to organisations, Oxford, UK: Elsevier Science Ltd, pp. 3-20. 
Näkki, P., and Koskela-Huotari, K. 2012. "User Participation in Software Design via Social Media: Experiences from a Case Study with Consumers," AIS Transactions on HumanComputer Interaction (4:2), pp. 129-152.

Obendorf, H., Janneck, and Finck, M. 2009. "Inter-Contextual Distributed Participatory Design: Communicating design philosophies and enriching user experience," Scandinavian Journal of Information Systems (21:1), pp. 50-76.

Öberg, K.D., Gumm, D., and Naghsh, A.M. 2009. “A Special Issue Editorial - Distributed PD: Challenges and opportunities," Scandinavian Journal of Information Systems (21:1), pp. 2326.

Sarker, S., Sarker, S., and Sidorova, A. 2006. “Understanding Business Process Change Failure: An Actor-Network Perspective," Journal of Management Information System (23:1), pp. 5186.

Schön, D.A. 2003. The Reflective Practitioner. How Professionals Think in Action, NY: Basic Books.

Stacey, R. D. 2003. Strategic Management and Organisational Dynamics: The Challenge of Complexity ( $4^{\text {th }}$ ed.), Harlow, UK: Financial Times, Prentice Hall.

Titlestad, O.H., Staring, K., and Braa, J. 2009. “Distributed Development to Enable User Participation: Multilevel design in the HISP network," Scandinavian Journal of Information Systems (21:1), pp. 27-50.

Truex, D.P., Baskerville, R., and Klein, H. 1999. "Growing Systems in Emergent Organizations," Communications of the ACM (42:8), pp. 117-123.

Van de Ven, H.A. 2007. Engaged Scholarship A Guide for organisational and social Research, NY: Oxford University Press.

Venkatesh, V., Brown, S.A, Bala, H. (2013). “Bridging the Qualitative-Quantitative Divide: Guidelines for Conducting Mixed Methods Research," MIS Quarterly (37:1), pp. 21-64.

Vidgen, R., and Wang, X. 2006. “Organizing for Agility: A Complex Adaptive Systems Perspective on Agile Software Development Process," in Ljungberg J., and Andersson, M. (eds.) Proceedings of the $14^{\text {th }}$ European Conference on Information Systems, Gothenburg, Sweden, pp. 1316-1327.

Vidgen, R., and Wang, X. 2009. “Coevolving Systems and the Organisation of Agile Software Development," Information Systems Research (20:3), pp. 355-376.

Volberda, H. W., and Levin. A. Y. 2003. “Guest editors' introduction: coevolutionary dynamics within and between firms: From evolution to co-evolution," Journal of Management Studies (40:8), pp. 2111-2136.

Walsham, G. 1995. “Interpretive Case Studies in IS Research: Nature and Method,” European Journal of Information Systems (4:2), pp.74-81.

Copyright: ( 2020 Kautz, Bjerknes, Fisher \& Jensen. This is an open-access article distributed under the terms of the Creative Commons Attribution-NonCommercial 3.0 Australia License, 
which permits non-commercial use, distribution, and reproduction in any medium, provided the original author and AJIS are credited.

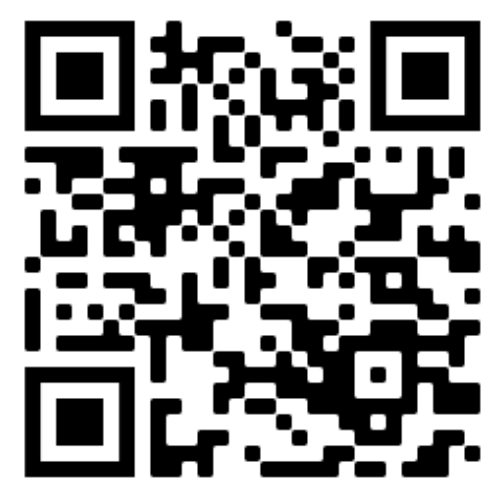

